Ontogenetic Increase in Archimedean Weight

of the Ostracod Chlamydotheca unispinosa (Baird)

\author{
ROBERT V. KESLING \\ and \\ FREDERICK C. CRAFTS
}

$\nabla$

Reprinted from

THE AMERICAN MIDLAND NATURALIST

Vol. 68, No. 1, pp. 149-153, July, 1962

University of Notre Dame Press

Notre Dame, Indiana 



\title{
Ontogenetic Increase in Archimedean Weight of the Ostracod Chlamydotheca unispinosa (Baird)
}

\author{
ROBERT V. KESLING and FREDERICK C. CRAFTS \\ The University of Michigan, Ann Arbor
}

\begin{abstract}
To investigate Przibram's Law for living ostracods, specimens of Chlamydotheca unispinosa (Baird) from an aquarium culture were weighed in water with a torsion microbalance. For each interval representing an ecdysis between the fifth and eighth instars, the Archimedean weight increases remarkably close to twice its former value. For the interval representing the ecdysis between the eighth instar and the adult, the increase is slightly more. The greater increase during the final molting probably results from the development of sex organs as maturity is attained.
\end{abstract}

\section{INTRODLCTION}

To our knowledge, this is the first attempt to test the basic concept of Przibram's Law for living ostracods, namely, that the animal doubles its weight during each ecdysis. Previous evaluations have been based on linear dimensions of the carapace, rather than the weight of the total ostracod.

By its general body plan and its small size, an ostracod presents two difficulties in weighing. First, the soft thin-walled body and appendages lie inside the bivalved carapace. When removed from water, the ostracod clamps the valves together, trapping water between the body and the hypodermis lining the carapace. Anesthetized, it will relax the adductor muscles and allow the valves to gape. The desiccation necessary to remove the water from around body and appendages undoubtedly also occasions a loss of water from the tissues. Since we were unable to devise a means of obtaining actual (dry) weight, we had to use the Archimedean or reduced weight in water.

Second, ostracods are essentially microscopic. Even such a large species as Chlamydotheca unispinosa must be weighed in units at least as small as micrograms. Commercial microbalances do not attain this accuracy. Our greatest difficulty was designing and calibrating a torsion microbalance capable of weighing specimens.

\section{Previous Work}

Przibram (1931:26) supposed that all crustaceans double their weight during ecdysis. Other investigators have shown that this relationship does not hold for many groups, including the isopod Asellus, the cladoceran Daphnia, the edible crabs Callinectes and Cancer, the lobster Homarus, the caprellid Pseudocaprella, the shorecrab Carcinus, and others. Needham (1950) offers a summary and excellent bibliography on studies of growth in Crustacea. 
Previous attempts to evaluate growth patterns in living ostracods have only utilized linear measurements. Most studies of Przibram's Law for fossil ostracods have been similarly restricted to comparison of increase in length, height, and width of the carapace against the theoretical value of 1.26 (the cube root of 2). Results presented from our laboratory (1952 to 1957) indicate that fossil ostracods do increase by a linear factor of about 1.26 , with the population of each instar clustered about the mean in some species but dispersed in others. Indeed, the factor so closely approximates 1.26 that a slide rule has been devised to determine quickly the instars of a species by their linear dimensions (Kesling, 1953b). The slide rule works well for nearly all species treated.

Only one study has involved weighing techniques. Reduced weights of carapaces in the Devonian Welleria meadowlakensis Kesling and Takagi (1961), as established with a Zeuthen Cartesian-diver apparatus, differ by a factor very close to the ideal 2 .

\section{Material Studied}

Chlamydotheca unispinosa (Baird) was selected for study primarily because it is one of the largest freshwater ostracods that thrives well in aquaria. Although reported native to Jamaica and the Sandwich Islands (Baird, 1862; Müller, 1912), it is an interloper in shipments of tropical fish and unexpectedly appears in contaminated laboratory cultures. Presumably, the start of our ostracod population was procured, unbeknown to all concerned, with some guppies from a dealer.

Chlamydotheca unispinosa is parthenogenetic, so that dimorphism does not enter into growth considerations. The species can be readily identified by the minute punctae, dark green streaks of the carapace, and the short sharp spine projecting from the posteroventral corner of the right valve. Ontogeny from hatching to adult takes only about 30 days.

In aerated aquaria, the ostracods multiplied rapidly on a supply of lettuce and tropical-fish food. Sufficient algae were present to discolor the water. One female was isolated in an aquarium, and the clone developed through her progeny supplied the specimens used for weighing.

\section{Microbalance}

Our weighing instrument is similar to that described by Neher (1938) and Lowry (1941) except that the torsion is applied to a long fine wire instead of a short quartz fiber. Such a microbalance is simple to construct. Inside a long substantial box with open sides, a thin wire is stretched between a flat metal spring at one end and the shaft of a vernier dial at the other. A crossarm is securely attached to the middle of the thin wire. From notches near the ends of the crossarm, twin balance cups made of very fine wire and aluminum foil are suspended, long enough to extend below the surface of water in a trough below. If a small weight is added to one of the cups, the cross- 
arm can again be brought to a horizontal position by turning the dial in the opposite direction. At this time, no twist is exerted on the half of the thin wire between the crossarm and the metal spring; all of the twist required to support the weight from the end of the crossarm is confined to the wire between the crossarm and the shaft of the dial.

In our microbalance the torsion wire is L.S. Standard Plate Gauge No. 30 (diameter $0.03175 \mathrm{~cm}$ ) "piano" wire $165.5 \mathrm{~cm}$ long (effective half-length for torsion, $82.75 \mathrm{~cm}$ ) with modulus of rigidity $7.118 \times 1011$ dynes $/ \mathrm{cm}^{2}$. The crossarm is Gauge No. 20 (diameter $0.09525 \mathrm{~cm}$ ) wire with effective half-length of $29.1 \mathrm{~cm}$ (from torsion wire to point of suspension of each balance cup). The torsion wire is cemented to spring, shaft of dial, and crossarm with sealing wax. Both the torsion wire and the water-filled trough are grounded to reduce static electricity. The level or "zero" position of the crossarm is established by a counterbalanced mirror mounted near the center of the crossarm, which reflects the image of cross hairs from a $35-\mathrm{mm}$ projector to a reference mark 20 meters away. The angle of twist on the torsion wire is found by a second small mirror mounted on the shaft of the dial, reflecting the image of cross hairs from another $35-\mathrm{mm}$ projector to a scale 20 meters away. The apparatus was used in our experiments in the basement under the Museum of Paleontology; where temperature is constant and air currents are negligible.

The use of this kind of microbalance involves two physical principles. The first is that the torque on a wire $\left(C\right.$, in $\left.\mathrm{gm} \mathrm{cm}^{2} / \mathrm{sec}^{2}\right)$ is directly proportional to the modulus of rigidity $\left(M\right.$, in dynes $\left./ \mathrm{cm}^{2}\right)$, the fourth power of the radius $(r$, in $\mathrm{cm})$, and the angle of twist $(\Theta$ in radians) and inversely proportional to twice the length of the wire $(L$, in $\mathrm{cm})$ :

$$
2 L C=M r^{4} \Theta .
$$

The second is that the torque can be created as the moment of force from an object of mass $(m$, in gm ) added to the crossarm at a certain distance from the torsion wire $(D$, in $\mathrm{cm})$ and subject to gravity $(g$, in $\left.\mathrm{cm} / \mathrm{sec}^{2}\right)$ :

$$
C=m D g \text {. }
$$

The general formula used in computations combines these two equations:

$$
2 L m D g=M r^{4} \Theta .
$$

In calibrating the microbalance, the reduced weight of numerous sheets of aluminum foil $\left(10000 \mathrm{~cm}^{2}\right)$ was found with a conventional laboratory balance. Small strips $(0.1 \times 1 \mathrm{~cm})$ were cut under a microscope and weighed under water with the microbalance; ten strips were used to yield an average. The relationship between $m$ and $\Theta$ established in this manner was then used as a factor to compute the mass of any object from the angle of twist which was necessary to support it. The accuracy of the microbalance was determined to be \pm 1.8 micrograms. 


\section{Procedure}

Weighing of each ostracod involves preparation of the animal, operation of the microbalance, and computations.

To avoid contamination by detritus from the aquarium, each ostracod is removed with a clean pipette to a small bowl containing clean water. The animal's carapace is brushed carefully under water with a small brush to dislodge detritus. The ostracod is again transferred with a pipette to a small vial containing 15 per cent solution of sodium nembutal (each $\mathrm{ml}$ of stock contains $60 \mathrm{mgm}$ of pentobarbital sodium, 10 per cent alcohol, and 20 per cent propylene glycol).

When the ostracod is completely anesthetized, it is transferred with pipette to a small bowl containing distilled water, which is then agitated to wash away the sodium nembutal solution. Since the adductor muscles relax and the valves gape in the anesthetized ostracod, the bath in water probably clears the solution from the body and appendages as well as from the valves. The ostracod is once again transferred to a small bowl of distilled water. Recovery usually follows within several minutes, so that the weighing must proceed immediately.

The projectors are switched on, the dial adjusted so that the reflection from the crossarm mirror hits the reference mark, and the reflection from the shaft-mounted mirror is noted on the scale. The ostracod is transferred with a pipette to one of the balance cups, the dial turned to restore the crossarm to the initial position, and the new reflection noted on the scale.

The angle of each reflection to the scale is determined from the tangent produced by departure from horizontal divided by the distance from the torsion wire to the scale. Even for the largest ostracod weighed, the angle is quite small.

\section{Results}

The following table lists the weights ( \pm 1.8 micrograms) for two ostracods in the fifth instar and ten in each of the sixth, seventh, eighth, and adult instars.

Weights of Specimens of Chlamydotheca unispinosa (in micrograms)

\begin{tabular}{ccccc}
\hline \hline Adult & $\begin{array}{c}\text { Eighth } \\
\text { Instar }\end{array}$ & $\begin{array}{c}\text { Seventh } \\
\text { Instar }\end{array}$ & $\begin{array}{c}\text { Sixth } \\
\text { Instar }\end{array}$ & $\begin{array}{c}\text { Fifth } \\
\text { Instar }\end{array}$ \\
\hline 458 & 225 & 112 & 58 & 30 \\
454 & 219 & 110 & 57 & 25 \\
446 & 217 & 107 & 55 & \\
434 & 212 & 105 & 55 & \\
433 & 209 & 104 & 53 & \\
431 & 209 & 102 & 52 & \\
428 & 207 & 102 & 52 & \\
426 & 202 & 102 & 50 & \\
412 & 200 & 100 & 48 & \\
406 & 195 & 99 & 47 & 27.5 \\
Mean & 209.5 & 104.3 & 52.7 & \\
\hline
\end{tabular}


Only a cursory inspection of the weights is needed to see that each instar is clearly separable from those smaller and larger, although the specimens in each instar vary in weight. The increase from the sixth to serenth instars is 1.98; from the seventh to eighth, 2.01; and from the eighth to the adult, 2.07. These values are very close to the theoretical value of 2 proposed by Przibram, and tend to substantiate the inferences drawn from linear measurements of living and fossil populations. Perhaps the greater increase from the eighth instar to the adult can be attributed to the development of the sex organs.

Possibly greater accuracy in weighing could be achieved by using finer wire in the torsion microbalance. Other experiments with living species are needed to test Przibram's Law for ostracods.

\section{REFERENCES}

BAIRD, W. 1862. Description of some new species of entomostracous Crustacea. Ann. Mag. Nat. Hist., ser. 3, 10(55):1-6.

Keslivg, R. V. 1952a. A study of Ctenoloculina cicatricosa (Warthin). Contrib. Mus. Paleontol. Univ. Mich., 9(8):247-290.

$-1952 b$. Doubling in size of ostracod carapaces in each molt stage. $J$. Paleontol., 26(5):772-780.

1953a. A beyrichiid ostracod from the Middle Devonian Wanakah shale. Bull. Buffalo Soc. Nat. Sci., 21 (2):19-24.

$-1953 b$. A slide rule for the determination of instars in ostracod species. Contrib. Mus. Paleontol. Univ. Mich., 11(5):97-109.

1954. Ostracods from the Middle Devonian Dundee limestone in northwestern Ohio. Ibid., 11(8):167-186.

1957. A chart useful for study of ostracod carapaces. Ibid., 14(2): $17-20$.

aNd M. J. Copeland. 1954. A new kirkbyid ostracod from the Wanakah member of the Middle Devonian Ludlowville formation in western New York. Ibid., 11(7):153-165.

AND G. C. Soronex. 1957. The ontogeny and ecology of Welleria aftonensis Warthin, a Middle Devonian ostracod from the Gravel Point formation of Michigan. Ibid., 14(5):41-55.

AND R. S. TAkagr. 1961. Evaluation of Przibram's Law for ostracods by use of the Zeuthen Cartesian-diver weighing technique. Ibid., 17(1): $1-58$.

AND P. L. WAGNER. 1956. Silurian ostracods collected by Dr. Carl Ludwig Rominger from glacial deposits in Germany. Part I. Introduction and review of Beyrichia tuberculata (Klöden). Ibid., 13(2): 33-55.

Lowry, O. H. 1941. A quartz fiber balance. J. Biol. Chem., 140:183-189.

Müller, G. W. 1912. Ostracoda. Das Tierreich, Eine Zusammenstellung und Kennizeichnung der rezenten Tierformen, 31 :xxxiii +434 p. K. Preuss. Akad. Wiss. Berlin.

NeEdhaM, A. E. 1950. Growth and regeneration rates in relation to age in Crustacea. J. Gerontol., 5(1):5-16.

Neher, H. V. 1938. The use of fused silica, p. 188-216. In John Strong, H. V. Teher, A. E. Whitford, C. H. Cartwright, and Roger Hayward, Procedures in Experimental Physics. Prentice-Hall, Inc., New York. $\mathrm{x}+642 \mathrm{p}$.

Przibram. H. 1931. Connecting laws in animal morphology. Four lectures held at the University of London, March, 1929. Univ: London Press. 62 p. 
